\title{
Popularisation of optical phenomena: establishing the first Ibn Al-Haytham workshop on photography
}

Hamid-Eddine Bouali, Mourad Zghal, Zohra Ben Lakhdar

Hamid-Eddine Bouali, Mourad Zghal, Zohra Ben Lakhdar, "Popularisation of optical phenomena: establishing the first Ibn Al-Haytham workshop on photography," Proc. SPIE 9664, Ninth International Topical Meeting on Education and Training in Optics and Photonics, 966422 (24 October 2005); doi: $10.1117 / 12.2207764$

Event: Ninth International Topical Meeting on Education and Training in Optics and Photonics, 2005, Marseille, France 


\title{
Ref ETOP080
}

\section{Popularisation of Optical Phenomena: Establishing the First Ibn Al-Haytham Workshop on Photography}

\author{
Hamid-Eddine Bouali ${ }^{1}$, Mourad Zghal ${ }^{1,2}$ and Zohra Ben Lakhdar ${ }^{1}$ \\ 1 Optical Society of Tunisia, Physics Department, Faculty of Sciences of Tunis, Campus \\ University, Tunis 1060, Tunisia \\ 2 Sup'Com, Cité Technologique des Communications, 2083 Ariana, Tunisia \\ Phone: +216 71857 000; Fax: +216 71856 829; mourad.zghal@supcom.rnu.tn
}

\begin{abstract}
Within the framework of its scientific activities, the Optical Society of Tunisia organized the first photographic workshop called Ibn Al-Haytham session. This activity enabled, through conferences, the evocation of the research done by one of the most distinguished and prolific mathematicians in the medieval tradition of Arabic Islamic science. The camera obscura that he thoroughly studied was the theme of a training where more than twenty participants build and used this basic camera. The adopted training approach based on active teaching and learning made possible the achievements of interesting results in spite of the heterogeneity of the group of trainees.
\end{abstract}

Training, optics, photography, Ibn Al-Haytham

\section{Keywords}

\section{Introduction}

\section{Summary}

Within the framework of its scientific activities, the Optical Society of Tunisia organized the first photographic workshop called Ibn Al-Haytham session. This activity enabled, through conferences, the evocation of the research done by one of the most distinguished and prolific mathematicians in the medieval tradition of Arabic Islamic science. The workshop started with a conference dealing with the scientific achievements of Al-Hasan Ibn al-Haytham (Latinized as Alhacen or Alhazen) who became known in Europe in the thirteenth century as the author of a monumental book on optics, which Latin editions influenced Kepler and Descartes. In his Kitâb al-Manâzir (De aspectibus), the eleventh-century scholar offered a new solution to the problem of vision, combining experimental investigations of the behavior of light with inventive geometrical proofs and constant forays into the psychology of visual perception, all systematically tied together to form a coherent alternative to the Euclidean and Ptolemaic theories of "visual rays" issuing from the eye. He established that rays of light start from the object to travel towards the eye, and not the reverse. Ibn al-Haytham also explained the use of the camera obscura in observing solar eclipses. He established the theorem of the cotangent in determining the direction of the Mecca. He correctly explained the atmospheric refraction and the augmentation of the apparent diameter of the sun and moon when they are near the horizon. He discovered spherical aberration. He determined that because the Milky Way had no parallax, it was very remote from the earth and did not belong to the atmosphere.

\section{Training methodology}

A basic photography training was then established for a group of twenty persons having their ages vary between 12 and 50 years. The trainees were mainly composed of high-school pupils and students but also teachers and administrators. This training was designed for any 
photographer just starting out. It contains 4 major lessons on how to build and use a camera obscura using only sheets of paper.

\subsection{Camera obscura: principle and history}

The first two lessons were dedicated to the history of the Camera Obscura and on how to construct it in a simple way. It was explained that, the Camera Obscura (Latin for Dark room) was a dark box or room with a hole in one end. If the hole was small enough, an inverted image would be seen on the opposite wall. This magic is explained by a simple law of the physical world. Light travels in a straight line and when some of the rays reflected from a bright subject pass through a small hole in thin material they do not scatter but cross and reform as an upside down image on a flat surface held parallel to the hole. A demonstration of this optical phenomenon was performed by the lecturer. This law of optics was known in ancient times. The earliest mention of this type of device was by the Chinese philosopher Mo-Ti (5th century BC). He formally recorded the creation of an inverted image formed by light rays passing through a pinhole into a darkened room. He called this darkened room a "collecting place" or the "locked treasure room." Aristotle (384-322 BC) understood the optical principle of the camera obscura. He viewed the crescent shape of a partially eclipsed sun projected on the ground through the holes in a sieve, and the gaps between leaves of a plane tree. It is said that Roger Bacon invented the camera obscura just before the year 1300 , but this has never been accepted by scholars; more plausible is the claim that he used one to observe solar eclipses. In fact, the Arabian and scientist Alhazen (c.965 - 1039) gave a full account of the principle including experiments with five lanterns outside a room with a small hole. He described what can be called a camera obscura in his writings; manuscripts of his observations are to be found in the India Office Library in London. In his essay "On the form of the Eclipse" he wrote: "The image of the sun at the time of the eclipse, unless it is total, demonstrates that when its light passes through a narrow, round hole and is cast on a plane opposite to the hole it takes on the form of a moon-sickle. The image of the sun shows this peculiarity only when the hole is very small. When the hole is enlarged, the picture changes....".

The earliest record of the uses of a camera obscura can be found in the writings of Leonardo da Vinci (1452-1519). In 1490 he gave two clear descriptions of the camera obscura in his notebooks. Many of the first camera obscuras were large rooms like that illustrated by the Dutch scientist Reinerus Gemma-Frisius for use in observing a solar eclipse at Louvain on January 24, 1544 Later he used this illustration of the event in his book De Radio Astronomica et Geometrica, 1545 (see Fig.1).

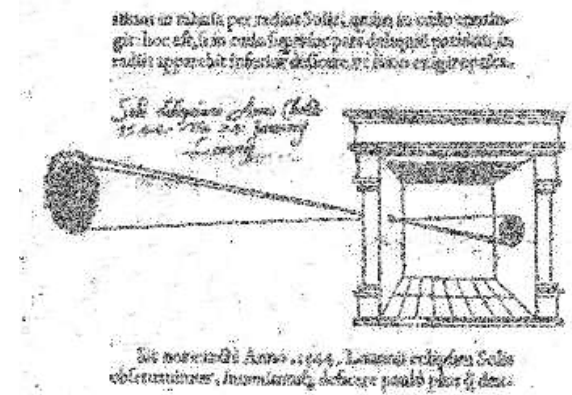

Figure 1. Camera Obscura by Reinerus Gemma-Frisius in 1544.

It is thought to be the first published illustration of a camera obscura 
The image quality was improved with the addition of a convex lens into the aperture in the mid sixteenth 16th century and the later addition of a mirror to reflect the image down onto a viewing surface. Once again Roger Bacon's name is associated with this; some have claimed that it was he who invented spectacles. Gerolomo Cardano (1501- 1576), an Italian mathematician, introduced a glass disc in place of a pinhole in his camera. It is claimed that because Italian lenses were by-convex, they seemed to resemble the brown lentils they used to make soup - so the lens came from the Latin for lentil. Giovanni Battista Della Porta (15381615 ) in his 1558 book Magiae Naturalis recommended the use of this device as an aid for drawing for artists. He published what is believed to be the first account of the possibilities as an aid to drawing. It is said that he made a huge "camera" in which he seated his guests, having arranged for a group of actors to perform outside so that the visitors could observe the images on the wall. The term "camera obscura" was first used by the German astronomer Johannes Kepler in the early 17th century. He used it for astronomical applications and had a portable tent camera for surveying in Upper Austria. The development of the camera obscura took two tracks. One of these led to the portable box device that was a drawing tool. In the 17th and 18th century many artists were aided by the use of the camera obscura. Jan Vermeer, Canaletto, Guardi, and Paul Sandby are representative of this group. By the beginning of the 19th century the camera obscura was ready with little or no modification to accept a sheet of light sensitive material to become the photographic camera.

\subsection{Construction of the camera obscura}

The next step was to initiate the group to the fabrication of their own camera obscura using only paper. The camera was designed to obtain an image which dimensions were $13 \times 18 \mathrm{~cm}$. Due to the heterogeneity of the group, and as all this was very new for the trainees, the lectures have to be pitched at the right level, using minimum mathematical formulas and concepts and everyday illustrations. More than once, the attention of participants was drawn to the following precautions such as quality of cutting of the edges of the hole that must be a circle as perfect as possible; the two faces of the camera must be well parallels; the camera has to be immobile while taking a photo, etc. Throughout the training, trainees discuss their project progress; and suggestions are given as they report in front of other trainees. The mentorship was enhanced by the relevance to optics to real life and the beauty that photography can create. The students were beyond learning hard core optics to making their own photography viewing results of their camera. The participants' photos were discussed and exposed in the city of sciences of Tunis. At the end of the course, the participants completed an optional exam that helped them better track their understanding of the techniques of basic photography. An evaluation of the training was held at the end of the activity and certificate of attendance were delivered to participants.

\section{Concluding remarks}

The methodology used to introduce new techniques and knowledge to a heterogeneous group was based on an active learning. The training approach has been chosen to push trainees to be active and to maximize their skills in optics and photography. The trainees received theoretical instructions in a comprehensible way. They learn the conditions, and go through the process of making a photograph of their favorite objects from start to finish. Through their interactions with the mentors, trainees were better able to understand the scientific way of thinking and doing things. The majority of participants enjoy the participation to the activity. It has proven to be an unforgettable experience for all participants. The second edition of this activity will focus on other aspects of photography such as digital effects. 


\section{Acknowledgements}

The authors gratefully acknowledge, Hassen AKROUT, Chair of the Executive Committee of "Association Jeunes Sciences de Tunisie", for his full and active support without which, this activity would not have taken place. They also thank the city of sciences of Tunis for having accomodated the activity and to offered its splendid landscapes to the camera of the participants.

\section{References}

1. Abdelhamid Sabra, "Ibn al-Haytham, Brief life of an Arab mathematician: died circa 1040," Harvard Magazine, Sept. 2003, pp 54-55.

2. http://brightbytes.com/cosite/cohome.html

3. http://www.acmi.net.au/AIC/CAMERA_OBSCURA.html 